\title{
Regulation of Presynaptic NMDA Responses by External and Intracellular pH Changes at Developing Neuromuscular Synapses
}

\author{
Yu-Hwa Chen, ${ }^{1}$ Mei-Lin Wu, ${ }^{2}$ and Wen-Mei Fu' ${ }^{1}$ \\ Departments of ${ }^{1}$ Pharmacology and ${ }^{2}$ Physiology, College of Medicine, National Taiwan University, Taipei, Taiwan 100, \\ Republic of China
}

\begin{abstract}
NMDA receptors play important roles in synaptic plasticity and neuronal development. The functions of NMDA receptors are modulated by many endogenous substances, such as external $\mathrm{pH}\left(\mathrm{pH}_{\mathrm{e}}\right)$, as well as second messenger systems. In the present study, the nerve-muscle cocultures of Xenopus embryos were used to investigate the effects of both external and intracellular $\mathrm{pH}\left(\mathrm{pH}_{\mathrm{i}}\right)$ changes on the functional responses of presynaptic NMDA receptors. Spontaneous synaptic currents (SSCs) were recorded from innervated myocyte using whole-cell recordings. Local perfusion of NMDA at synaptic regions increased the SSC frequency via the activation of presynaptic NMDA receptors. A decrease in $\mathrm{pH}_{\mathrm{e}}$ from 7.6 to 6.6 reduced NMDA responses to $23 \%$ of the control, and an increase in $\mathrm{pH}_{\mathrm{e}}$ from 7.6 to 8.6 potentiated the NMDA responses in increasing SSC frequency. The effect of NMDA on intracellular $\mathrm{Ca}^{2+}$ concentration $\left(\left[\mathrm{Ca}^{2+}\right]_{\mathrm{i}}\right)$ was also affected by $\mathrm{pH}_{\mathrm{e}}$ changes: external acidification inhibited and alkalinization potentiated $\left[\mathrm{Ca}^{2+}\right]_{\mathrm{i}}$ in-
\end{abstract}

L-Glutamate plays an important role as an excitatory synaptic neurotransmitter in the mammalian CNS (Watkins and Evans, 1981; Foster and Fagg, 1984). Evidence has accumulated that at least three types of ionotropic receptors for glutamate exist on neuronal postsynaptic membranes: AMPA, kainate, and NMDA receptors (Monaghan et al., 1989). NMDA receptors possess high $\mathrm{Ca}^{2+}$ permeability and serve many functions in neuronal development, synaptic plasticity, and acquisition of memory (Hollmann and Heinemann, 1994; McBain and Mayer, 1994). However, activation of these receptors also can contribute to the pathology of epilepsy (Dingledine et al., 1990; Meldrum, 1992), stroke (Choi, 1990, 1992), and neurodegenerative disorders such as Alzheimer's disease, amyotrophic lateral sclerosis, and Huntington's disease (Beal, 1992). Therefore, the regulation of NMDA receptor activity is important in the CNS.

NMDA receptors are controlled by many endogenous substances as well as second messenger systems (Hollmann and Heinemann, 1994; McBain and Mayer, 1994). Among the ionotropic glutamate receptors, the NMDA receptor displays a unique sensitivity to extracellular $\mathrm{pH}\left(\mathrm{pH}_{\mathrm{e}}\right)$. In mammalian central neurons, NMDA-evoked currents were significantly enhanced by extracellular alkaline shifts in $\mathrm{pH}$ of a few tenths. On

Received Oct. 20, 1997; revised Jan. 27, 1998; accepted Jan. 29, 1998.

This work was supported by research Grant NSC 87-2314-B002-303 from the National Science Council. We thank Mr. I. S. Peng for help in preparing this manuscript.

Correspondence should be addressed to Dr. Wen-Mei Fu, Department of Pharmacology, College of Medicine, National Taiwan University, Taipei, Taiwan 100, Republic of China.

Copyright (C) 1998 Society for Neuroscience $\quad 0270-6474 / 98 / 182982-09 \$ 05.00 / 0$ creases induced by NMDA. Intracellular $\mathrm{pH}$ changes of single soma were measured by ratio fluorometric method using 2,7bis (carboxyethyl)-5,6-carboxyfluorescein (BCECF). Cytosolic acidification was used in which $\mathrm{NaCl}$ in Ringer's solution was replaced with weak organic acids. Acetate and propionate but not methylsulfate substitution caused intracellular acidification and potentiated NMDA responses in increasing SSC frequency, intracellular free $\mathrm{Ca}^{2+}$ concentration, and NMDA-induced currents. On the other hand, cytosolic alkalinization with $\mathrm{NH}_{4} \mathrm{Cl}$ did not significantly affect these NMDA responses. These results suggest that the functions of NMDA receptors are modulated by both $\mathrm{pH}_{\mathrm{e}}$ and $\mathrm{pH}_{\mathrm{i}}$ changes, which may occur in some physiological or pathological conditions.

Key words: NMDA receptor; NMDA-induced current; intracellular alkalinization; cytosolic acidification; extracellular $\mathrm{pH}$ change; developing motoneuron

the contrary, a decrease in $\mathrm{pH}_{\mathrm{e}}$ was shown to reduce NMDA receptor-mediated cation conductance dramatically in cultured central neurons (Tang et al., 1990; Vyklicky et al., 1990; Traynelis and Cull-Candy, 1991; Takahashi and Copenhagen, 1996). Both extracellular and intracellular $\mathrm{pH}$ are modulated in many physiological and pathological conditions. Excitatory synaptic transmission in the CNS has been reported to be associated with a rapid alkalinization of the extracellular space (Chesler, 1990; Chesler and Kaila, 1992). On the other hand, under normal conditions the $\mathrm{pH}_{\mathrm{i}}$ is decreased after prolonged neuronal activity (Chesler and Kaila, 1992). In addition, NMDA is reported to reduce neuronal $\mathrm{pH}_{\mathrm{i}}$ in central neurons and in spinal motoneurons (Edres et al., 1986; Dixon et al., 1993; Hartley and Dubinsky, 1993; Irwin et al., 1994). Whether the NMDA receptor is modulated by intracellular $\mathrm{pH}$ shifts is still unknown. Recently, we found that glutamate, which is also reported to be co-released from some cholinergic nerve terminals (Vyas and Bradford, 1987; Israel et al., 1993; Meister et al., 1993), markedly increased the frequency of spontaneous synaptic currents (SSCs) at embryonic neuromuscular synapses via the activation of NMDA and nonNMDA receptors ( $\mathrm{Fu}$ et al., 1995). SSC frequency increased markedly in response to the local perfusion of glutamate at the synaptic regions, whereas only a slight increase was observed when perfusion was performed at the soma. Furthermore, local perfusion of NMDA to the growth cone induced an inward current (our unpublished observation). These results indicate the existence of NMDA receptors at the developing motor nerve terminals. In this study, we further investigated the functional regulation of presynaptic $\mathrm{NMDA}$ receptors by both $\mathrm{pH}_{\mathrm{e}}$ and $\mathrm{pH}_{\mathrm{i}}$ 
changes. It was found that intracellular acidification potentiated the responses to NMDA in increasing SSC frequency, intracellular free $\mathrm{Ca}^{2+}$ concentration, and NMDA-induced currents, whereas intracellular alkalinization did not significantly affect these responses.

\section{MATERIALS AND METHODS}

Cell culture. Xenopus nerve-muscle cultures were prepared as reported previously (Tabti and Poo, 1991). Briefly, the neural tube and the associated myotomal tissues of 1-d-old Xenopus embryos (stages 20-22) were dissociated in $\mathrm{Ca}^{2+}$ - and $\mathrm{Mg}^{2+}$-free Ringer's solution supplemented with EDTA. The cells were plated onto clean glass coverslips and were used for experiments after $24 \mathrm{hr}$ at room temperature $\left(20-22^{\circ} \mathrm{C}\right)$. The culture medium consisted of 50\% (v/v) Ringer's solution $(115 \mathrm{~mm}$ $\mathrm{NaCl}, 2 \mathrm{~mm} \mathrm{CaCl}, 1.5 \mathrm{~mm} \mathrm{KCl}, 10 \mathrm{~mm}$ HEPES, pH 7.6), 49\% L-15 Leibovitz medium (Sigma, St. Louis, MO), $1 \%$ fetal bovine serum (Life Technologies, Grand Island, NY), and antibiotics (100 U/ml penicillin and $100 \mu \mathrm{g} / \mathrm{ml}$ streptomycin).

Electrophysiology. Whole-cell patch-clamp recording methods followed those described by Hamill et al. (1981). Patch pipettes were pulled with a two-stage electrode puller (pp-83, Narishige, Tokyo, Japan), and the tips were polished immediately before the experiment using a microforge (MF-83, Narishige). SSCs were recorded from innervated myocytes by whole-cell recording in the voltage-clamp mode. Recordings were made at room temperature in the Ringer's solution. For whole-cell recordings of myocytes, the solution inside the recording pipette contained $150 \mathrm{mM}$ $\mathrm{KCl}, 1 \mathrm{~mm} \mathrm{NaCl}, 1 \mathrm{~mm} \mathrm{MgCl}_{2}$, and $10 \mathrm{~mm}$ HEPES, $\mathrm{pH}$ 7.2. The extent of the potentiation was measured by the frequency ratio of SSCs, which is defined as the ratio of SSC frequency at peak level observed during application of drugs compared with the mean frequency observed before drug treatment. NMDA-induced currents were recorded from soma. The solution inside the recording pipette contained $145 \mathrm{~mm} \mathrm{CsCl}, 0.1 \mathrm{~mm}$ $\mathrm{CaCl}_{2}, 3 \mathrm{~mm} \mathrm{MgCl}_{2}, 5 \mathrm{~mm}$ EGTA, $5 \mathrm{~mm}$ HEPES, pH 7.2, and $1 \mathrm{~mm}$ amphotericin $\mathrm{B}$ was added to internal solution to get perforated patch. The membrane currents passing through the patch pipette were recorded with a patch-clamp amplifier (Dagan 8900). The data were digitized using Neuro-corder (Neuro Data DR 390) and stored on a videotape for later playback onto a storage oscilloscope (Tektronix 5113, Beaverton, OR) or an oscillographic recorder (Gould RS3200, Valley View, OH). The Data 6100 waveform analyzer (Data Precision, Danvers, MA) was used to analyze the frequency of SSCs. For analysis of spontaneous events at high frequency when overlaps of current events occurred, the events were counted visually from chart records of an oscillographic recorder driven at high chart speeds $(25-100 \mathrm{~mm} / \mathrm{sec})$. Data are expressed as mean \pm SEM. Statistical significance was evaluated by Student's $t$ test.

Measurement of $\mathrm{pH}_{i}$. Measurement of $\mathrm{pH}_{\mathrm{i}}$ has been described in detail elsewhere (Wu et al., 1994). In brief, cultures were loaded with $5 \mu \mathrm{M}$ 2,7-bis (carboxyethyl)-5,6-carboxyfluorescein (BCECF-AM, Molecular Probes, Eugene, OR) for $5-10 \mathrm{~min}$ at room temperature in Ringer's solution and then washed with the same solution three times. A single soma was isolated by adjusting the slit width of the photomultiplier tube and excited by alternate flashes of 490 and $440 \mathrm{~nm}$ wavelength light, using a filter wheel (Cairn Research, Kent, England) rotating at $32 \mathrm{~Hz}$. The excitation light was transmitted to the cell under study using a $510 \mathrm{~nm}$ dichroic mirror under the microscope nosepiece, and the resulting fluorescence was collected via a $40 \times$ magnification oil-immersion lens. The overall sampling rate was $0.5 \mathrm{~Hz}$. The $490 / 440$ emission ratio from the intracellular BCECF was calculated and converted to a linear $\mathrm{pH}$ scale using in situ calibration data obtained at the end of the experiment by the nigericin technique. A calibration curve similar to that used by Wu et al. (1994) was established by measuring the fluorescence ratio values between $\mathrm{pH}_{\mathrm{i}} 4.5$ and 9.5. Between $\mathrm{pH}_{\mathrm{i}} 5.5$ and 9.0, the response is linear and fits the equation $\mathrm{pH}_{\mathrm{i}} \mathrm{p} K+\log \left[\left(R_{\max }{ }^{-\mathrm{R}}\right) /\left(R-R_{\min }\right]+\log \left(F_{440 \min } /\right.\right.$ $\left.F_{440 \max }\right)$, where $R$ is the ratio of $530 \mathrm{~nm}$ fluorescence at $490 \mathrm{~nm}$ excitation to $530 \mathrm{~nm}$ fluorescence at $440 \mathrm{~nm}$ excitation. $R_{\max }$ and $R_{\min }$ are the maximum and minimum ratio values from the data curve, and $K$ is the dissociation constant for the dye, taken as $55 \mathrm{~nm}$.

Measurement of intracellular $\mathrm{Ca}^{2+}$ levels. The intracellular concentration of free $\mathrm{Ca}^{2+}\left(\left[\mathrm{Ca}^{2+}\right]_{i}\right)$ in the soma was measured using the $\mathrm{Ca}^{2+}$ sensitive fluorescent dye fura-2. Cultures plated onto a $25 \mathrm{~mm}$ round coverslip (No. 1001, Assistent) were loaded with $2 \mu \mathrm{M}$ fura-2 AM (Molecular Probes) in Ringer's solution for $1 \mathrm{hr}$ at room temperature. The cells were then washed with the same solution. The fluorescence of a single soma was measured as indicated above except that the cell was excited by alternate flashes of 340 and $380 \mathrm{~nm}$ wavelength. The 340/380 emission ratio from the intracellular fura- 2 was calculated and converted to a linear $\mathrm{Ca}^{2+}$ scale by in situ calibration at the end of the experiment using the $\mathrm{Ca}^{2+}$ ionophore ionomycin $(5 \mu \mathrm{M}$, Sigma). The following equation (Grynkiewicz et al., 1985) was used to convert the fluorescence ratio into the intracellular $\mathrm{Ca}^{2+}$ concentration $\left[\mathrm{Ca}^{2+}\right]_{\mathrm{i}}=K_{\mathrm{d}}[(R-$ $\left.\left.R_{\min }\right) / R_{\max }-R\right]\left(S_{\mathrm{f} 2} / S_{\mathrm{b} 2}\right)$, where $R$ is the ratio of $510 \mathrm{~nm}$ fluorescence at $340 \mathrm{~nm}$ excitation to $510 \mathrm{~nm}$ fluorescence at $380 \mathrm{~nm}$ excitation, $R_{\max }(10$ mM Ca $\left.{ }^{2+}\right)$ and $R_{\min }\left(10 \mathrm{~mm}\right.$ EGTA in $\mathrm{Ca}^{2+}$-free Ringer's solution) are the maximum and minimum ratio values from the data curve, $K_{\mathrm{d}}$ is the dissociation constant for the dye, taken as $135 \mathrm{~nm}$ at room temperature, and $S_{\mathrm{f} 2} / S_{\mathrm{b} 2}$ is the ratio of the $380 \mathrm{~nm}$ signals determined at $R_{\min }$ and $R_{\max }$.

Because $\mathrm{Ca}^{2+}$ and $\mathrm{H}^{+}$are presumably competitive, we have tested whether the $340 / 380$ signal was affected by the change of $\mathrm{pH}_{\mathrm{i}}$ because of the possible $\mathrm{pH}$ sensitivity of fura-2. Three levels of $\mathrm{pH}(6.8,7.2$, and 7.8) were tested in $\mathrm{Ca}^{2+}$-free Ringer's solution supplemented with $2 \mathrm{~mm}$ EGTA using the free acid form of fura-2, and we found that there was little change in the $340 / 380$ ratio when the $\mathrm{pH}$ was changed $(6.8,7.8$, and 7.2); the first two points were the two extreme levels of $\mathrm{pH}_{\mathrm{i}}$ we have observed in our experiments. We used $\mathrm{Ca}^{2+}$-free Ringer's solution supplemented with 2 mM EGTA in the above test to mimic a similar level of resting $\left[\mathrm{Ca}^{2+}\right]_{\mathrm{i}}(\sim 70 \mathrm{nM})$ in Xenopus cultured spinal neurons.

Chemicals. The following chemicals were used: $\mathrm{NH}_{4} \mathrm{Cl}$ and sodium acetate (Sigma), sodium methylsulfate (Aldrich, Milwaukee, WI), sodium propionate (Hayashi, Osaka, Japan), and NMDA (RBI, Natick, MA).

\section{RESULTS}

\section{Regulation of NMDA responses in increasing SSC frequency by $\mathrm{pH}_{\mathrm{e}}$ changes}

In nerve-muscle cultures prepared from 1-d-old Xenopus embryos, synaptic contacts were established between dissociated spinal neurons and myocytes within the first day of culture. SSCs were readily detectable from the innervated myocytes by wholecell voltage-clamp recording. These currents have been shown to be caused by spontaneous ACh secretion from the neuron, because they are abolished by bath application of D-tubocurarine and unaffected by tetrodotoxin (Xie and Poo, 1986). It was found recently that there are NMDA receptors in the nerve terminals of developing motoneurons (Fu et al., 1995; Liou et al., 1996). We thus used these nerve-muscle cocultures to investigate the functional regulation of presynaptic NMDA receptors by $\mathrm{pH}$ changes. Figure 1 shows the recording of SSCs from an innervated myocyte. Local application of NMDA by pressure at synaptic regions with another glass microelectrode as indicated in the inset (pipette opening, $9 \mu \mathrm{m}$; pipette NMDA concentration, $150 \mu \mathrm{M}$ ) reversibly increased the SSC frequency (SSC frequency ratio was $13.7 \pm 3.4 ; n=21)$. The effects of changes in $\mathrm{pH}_{\mathrm{e}}$ on the NMDA responses were investigated by replacing normal Ringer's solution with $\mathrm{pH}_{\mathrm{e}} 6.6$ or 8.6 Ringer's solution. The $\mathrm{pH}$ was adjusted before the experiment with $1 \mathrm{~N} \mathrm{HCl}$ or $\mathrm{NaOH}$, respectively, and the $\mathrm{pH}$ value remained unchanged throughout the experiment (within 1 $\mathrm{hr}$ ). The change in extracellular $\mathrm{pH}$ from 7.6 to 6.6 or 8.6 did not by itself significantly affect the frequency of spontaneous ACh secretion (SSC frequency ratio was $1.2 \pm 0.1, n=5$, and $0.9 \pm 0.1$, $n=6$, respectively). The mean SSC amplitude in $\mathrm{pH} 6.6$ and 8.6 Ringer's solution also showed no significant change before NMDA application $(146.5 \pm 35.0 \mathrm{pA}, n=5$, and $154.7 \pm 19.3 \mathrm{pA}$, $n=4$, respectively; control SSC amplitude was $167.3 \pm 14.3 \mathrm{pA}$, $n=21$ ). However, changes in $\mathrm{pH}_{\mathrm{e}}$ range between 6.6 and 8.6 had different effects on the SSC potentiating action of NMDA. Alkalinization of external $\mathrm{pH}$ from 7.6 to 8.6 potentiated the NMDA effect by $195 \pm 34 \%$ of the control (SSC frequency ratio was $26.5 \pm 4.7, n=4$ ) (Figs. 1, 2A). On the other hand, acidification of external medium from $\mathrm{pH} 7.6$ to 6.6 antagonized the NMDA action to $23 \pm 12 \%$ of the control (SSC frequency ratio was $3.2 \pm$ 


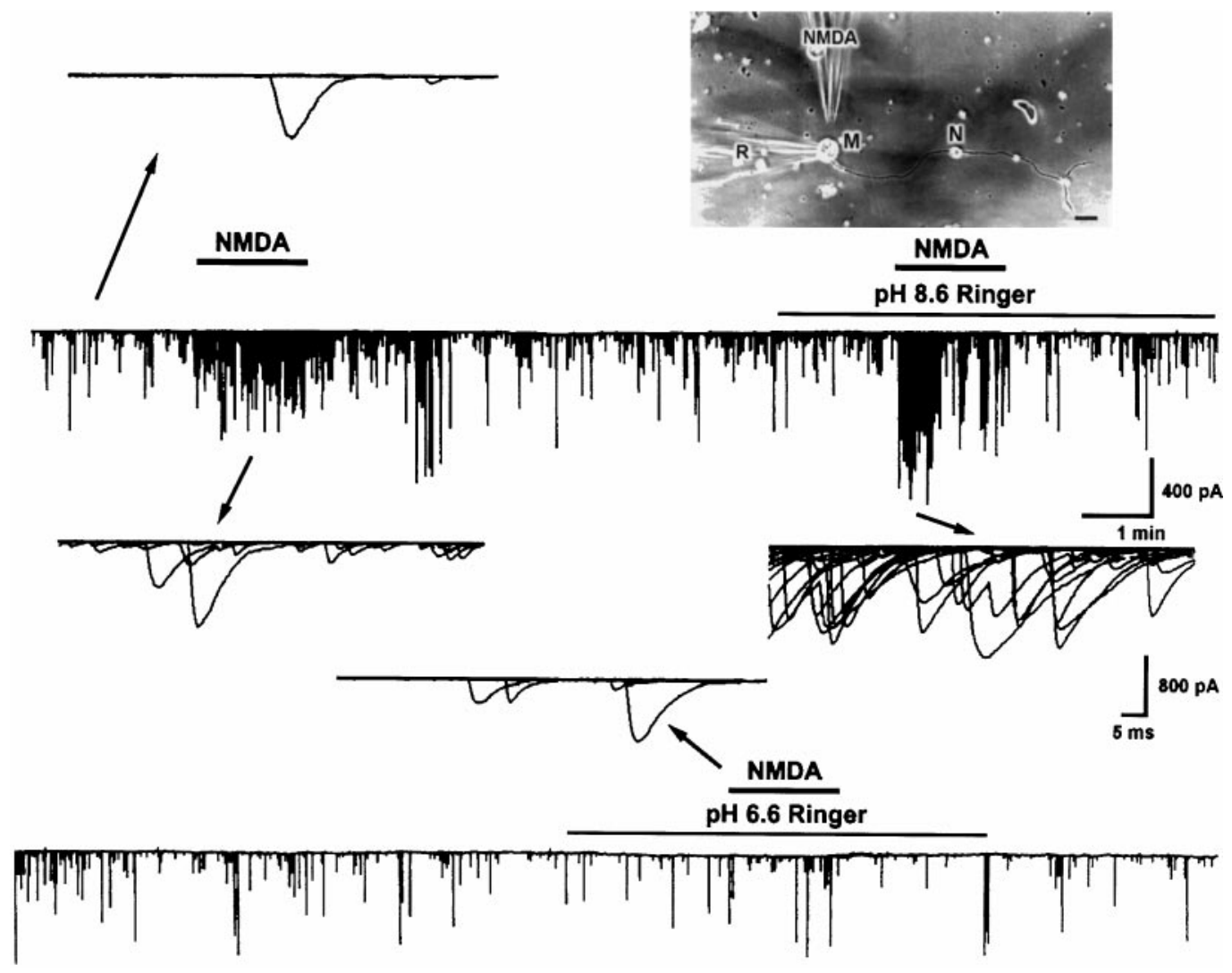

Figure 1. Effect of external $\mathrm{pH}$ changes on the SSC-increasing action of NMDA. Shown is continuous tracing of SSCs recorded from an innervated muscle cell in 1-d-old Xenopus culture. The myocyte was voltage-clamped at a potential of $-60 \mathrm{mV}$. Downward deflections are SSCs (filtered at $150 \mathrm{~Hz}$ ). The top right panel shows the relative position of patch pipette $(R)$ and NMDA pipette (NMDA). Local perfusion of NMDA at the synaptic region with another micropipette increased SSC frequency. NMDA responses were potentiated in $\mathrm{pH} 8.6$ Ringer's solution and antagonized in pH 6.6 Ringer's solution. Samples of superimposed SSCs in $1 \mathrm{sec}$ before and after NMDA treatment are shown at higher time resolution. Scale bar, $40 \mu \mathrm{m}$. $M$, Myocyte; $N$, neuron.

1.7, $n=4)$ (Figs. 1, 2A). The time course-response curves of the NMDA action in different external $\mathrm{pH}$ are shown in Figure $2 B$.

\section{Intracellular acidification enhances the responses to NMDA in increasing SSC frequency}

Cytosolic acidification was induced by weak organic acid substitution. Weak organic acid with $\mathrm{p} K_{\mathrm{a}}$ values in the range of 4-6 might allow selective acidification of cells. The protonated forms of such weak acids are more membrane permeable than their charged anionic forms and then dissociate intracellularly to liberate $\mathrm{H}^{+}$. Exposure of cells to weak acids is thus expected to result in an acute acid load to the cytoplasm. For these experiments, all the extracellular $\mathrm{NaCl}$ was replaced by the sodium salts of organic acids in normal Ringer's solution. Cytosolic $\mathrm{pH}$ in neuronal soma was monitored by the BCECF fluorescence method. The baseline $\mathrm{pH}_{\mathrm{i}}$ value was $7.17 \pm 0.03(n=46)$. The change of external solution from $\mathrm{pH}_{\mathrm{e}} 7.6$ to 6.6 or 8.6 caused only a slight cytosolic acidification of $0.14 \pm 0.02$ units $(n=6)$ or intracellular alkalinization of $0.11 \pm 0.04$ units $(n=4)$, respectively (Fig. 3A,D). However, a rapid intracellular acidification occurred after exposure with either acetate or propionate at a fixed $\mathrm{pH}$ of external medium $\left(\mathrm{pH}_{\mathrm{e}}\right.$ 7.6) (Fig. 3B,D). The $\mathrm{pH}_{\mathrm{i}}$ reached peak values of $6.86 \pm 0.12(n=8)$ with acetate and $6.78 \pm 0.15(n=7)$ with propionate. The intracellular fluid revealed an acidic shift of $0.2-0.4 \mathrm{pH}$ units. Removal of acetate or propionate results in a rebound cytosolic alkalinization. On the other hand, the peak value of $\mathrm{pH}_{\mathrm{i}}$ after exposure to methylsulfate did not show significant change $\left(\mathrm{pH}_{\mathrm{i}}\right.$ was $\left.7.09 \pm 0.03 ; n=6\right)$. The frequency and amplitude of SSC did not show significant change after exposure to organic acids alone for 1-2 min (SSC frequency ratio was $1.3 \pm 0.2, n=6$, with acetate; $1.4 \pm 0.3, n=6$, with propionate; and $1.1 \pm 0.2, n=4$, with methylsulfate, respectively; mean SSC amplitude was $150.9 \pm 21.6 \mathrm{pA}$ with acetate; $186.3 \pm$ $46.9 \mathrm{pA}$ with propionate; and $142.2 \pm 13.5 \mathrm{pA}$ with methylsulfate, respectively). However, substitution with either acetate or propionate markedly potentiated SSC frequency, increasing the action of NMDA (SSC frequency ratio was $35.5 \pm 7.2, n=6$, and $34.8 \pm$ $10.9, n=5$, respectively) (Figs. $4 A, B, 5 A$ ), while substitution of $\mathrm{NaCl}$ with strong organic acids such as methylsulfate resulted in no significant effect on the NMDA response (SSC frequency ratio was $8.5 \pm 2.6, n=4$ ) (Fig. $5 A$ ). We further investigated the effect of intracellular alkalinization on the NMDA responses. Exposure of the soma to $15 \mathrm{~mm} \mathrm{NH}_{4} \mathrm{Cl}$ resulted in a rapid increase of $\mathrm{pH}_{\mathrm{i}}(\Delta \mathrm{pH}=0.77 \pm 0.04 ; n=8)$, and the $\mathrm{pH}_{\mathrm{i}}$ in peak value was $7.67 \pm 0.14$ (Fig. $3 C, D$ ). The alkalinization seen during the first moments of exposure to $\mathrm{NH}_{4}{ }^{+}$is presumably caused by the rapid, passive entry of $\mathrm{NH}_{3}$ and its subsequent hydration to form $\mathrm{NH}_{4}{ }^{+}$ and $\mathrm{OH}^{-}$(Roos and Boron, 1981). Cytosolic alkalinization with $\mathrm{NH}_{4} \mathrm{Cl}$ alone for $2 \mathrm{~min}$ also did not significantly affect SSC frequency and amplitude (SSC frequency ratio was $0.9 \pm 0.2$; mean SSC amplitude was $145.4 \pm 28.5 \mathrm{pA} ; n=6)$. As shown in Figures $4 C$ and $5 A$, the NMDA responses were not affected after intracellular alkalinization (SSC frequency ratio was $12.6 \pm 3.6$, 

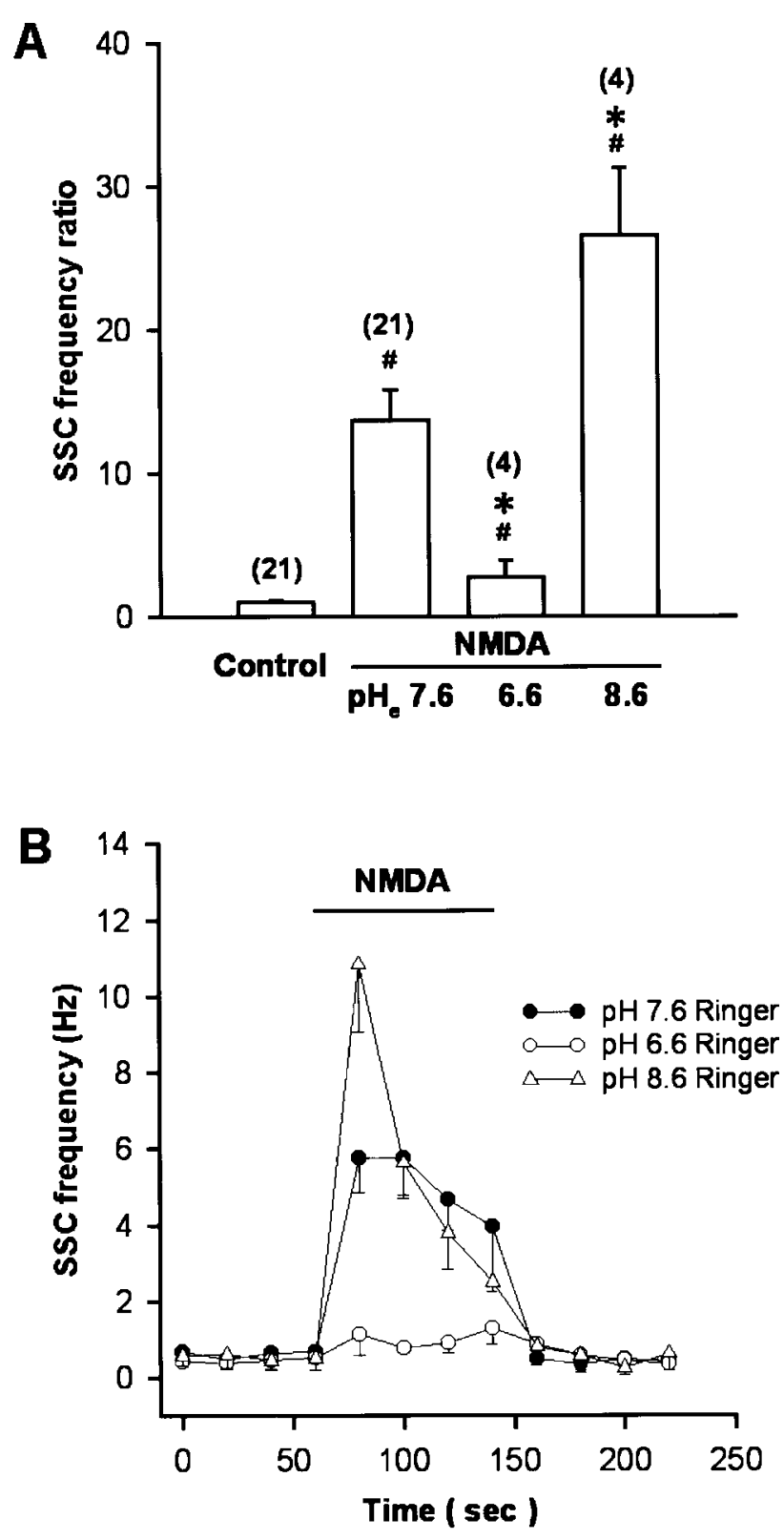

Figure 2. Summary of the effect of external pH changes on the SSCincreasing action of NMDA. Note that NMDA increased SSC frequency in normal $\mathrm{pH} 7.6$ Ringer's solution and the change of external $\mathrm{pH}$ to 8.6 potentiated NMDA action, whereas the reduction of external $\mathrm{pH}$ to 6.6 antagonized the SSC-increasing action of NMDA $(A)$. $B$, Time courseresponse curves in response to NMDA application. Data are presented as mean $\pm \operatorname{SEM}(n) .{ }^{*} p<0.05$ compared with control.

$n=6)$. The time course-response curves of the NMDA action on the cytosolic acidification and alkalinization are shown in Figure $5 B$.

\section{Modulation of NMDA effects on neuronal cytoplasmic} $\mathrm{Ca}^{2+}$ by the changes of $\mathrm{pH}_{\mathrm{e}}$ and $\mathrm{pH}_{\mathrm{i}}$

The intracellular concentration of free $\mathrm{Ca}^{2+}\left(\left[\mathrm{Ca}^{2+}\right]_{i}\right)$ in the soma was measured using the $\mathrm{Ca}^{2+}$-sensitive fluorescent dye fura-2. The basal neuronal $\left[\mathrm{Ca}^{2+}\right]_{\mathrm{i}}$ value was $70.2 \pm 4.6 \mathrm{~nm}(n=$ 32). Superfusion with $100 \mu \mathrm{M}$ NMDA in $\mathrm{pH} 7.6$ Ringer's solution increased $\left[\mathrm{Ca}^{2+}\right]_{\mathrm{i}}$ by $131.3 \pm 26.9 \mathrm{nM}(n=27)$. Responses to NMDA were affected by changing the $\mathrm{pH}$ of external medium.
Lowering the $\mathrm{pH}_{\mathrm{e}}$ from 7.6 to 7.0 or 6.6 decreased the $\left[\mathrm{Ca}^{2+}\right]_{\mathrm{i}}$ responses of NMDA to $64 \pm 10 \%$ and $23 \pm 7 \%$ of the control ( $n=4$ for each), respectively (Fig. $6 A, B)$, whereas increasing the $\mathrm{pH}_{\mathrm{e}}$ to 8.6 potentiated the $\left[\mathrm{Ca}^{2+}\right]_{\mathrm{i}}$ response of NMDA to $156 \pm$ $18 \%$ of the control $(n=4)$ (Fig. $6 A, B)$. By contrast, intracellular acidification by either acetate or propionate substitution enhanced the $\left[\mathrm{Ca}^{2+}\right]_{\mathrm{i}}$ response to NMDA. NMDA response was enhanced concentration-dependently by acetate substitution. Two-thirds of acetate substitution (two-thirds of the $\mathrm{NaCl}$ in Ringer's solution was replaced with equimolar sodium acetate) nonsignificantly increased NMDA response to $134 \pm 15 \%$ of control $(n=7)$, whereas $100 \%$ acetate substitution significantly increased the NMDA response to $168 \pm 28 \%(n=8)($ Fig. $7 A, D)$. Substitution with another weak acid propionate $(100 \%$ substitution) also increased NMDA response to $200 \pm 50 \%(n=5)$ (Fig. $7 B, D)$. However, intracellular alkalinization by $15 \mathrm{mM} \mathrm{NH}_{4} \mathrm{Cl}$ had no significant effect (Fig. 7C,D).

\section{Potentiation of NMDA-induced currents by intracellular acidification}

To determine directly the effect of intracellular acidification on the NMDA receptor, the soma of isolated spinal neurons was whole-cell voltage-clamped at $-60 \mathrm{mV}$ by using perforated patch. Local perfusion of NMDA with another micropipette (intrapipette concentration, $150 \mu \mathrm{M}$ ), as indicated in the right panel of Figure $8 A$, induced an inward current in the soma. Intracellular acidification by the substitution of all $\mathrm{NaCl}$ of Ringer's solution with either sodium acetate (Fig. $8 A$ ) or sodium propionate (Fig. $8 B$ ) enhanced the NMDA-induced currents $(134.6 \pm 6.4 \%$ and $162.6 \pm 14.0 \%$ of the control, respectively; $n=7$ for each). On the other hand, cytosolic alkalinization with $\mathrm{NH}_{4} \mathrm{Cl}$ did not significantly affect the NMDA-induced currents $(96.1 \pm 4.8 \%$ of the control, $n=6$ ) (Fig. $8 C$ ). However, changes of external $\mathrm{pH}$ from 7.6 to 8.6 or 6.6 enhanced and inhibited the NMDA-induced currents, respectively $[149.4 \pm 8.5 \%(n=6)$ and $37.1 \pm 6.6 \%$ $(n=4)$ of the control, respectively].

\section{DISCUSSION}

Many studies have revealed that second messengers such as $\mathrm{Ca}^{2+}$, cyclic nucleotides, and G-proteins modulate voltage-gated ion channels and ligand-gated receptor channels. Here we show that NMDA receptor-mediated synaptic potentiation, increase of intracellular $\mathrm{Ca}^{2+}$ concentration, and NMDA-induced currents are significantly influenced by the changes of either external or intracellular $\mathrm{pH}$. We have observed that external acidification inhibited but intracellular acidification enhanced NMDA responses. On the other hand, external alkalinization potentiated the NMDA action, whereas intracellular alkalinization had no significant effect. The modulation of NMDA responses by both external and internal $\mathrm{pH}$ changes might mediate some of the physiological and pathological actions of glutamate.

Our results are different from those reported by Tang et al. (1990), who showed that NMDA-activated current was rather insensitive to the change in internal $\mathrm{pH}$. The intracellular $\mathrm{pH}$ was altered in their study by filling the pipette with an internal solution of different values of $\mathrm{pH}$. The $\mathrm{pH}$ of intracellular fluid may be different from that of patch pipette as a result of the buffering capacity of cytoplasm and improper diffusion of patch pipette solution. We here acidified intracellular fluid by using a weak organic acid substitution. It has long been known that weak acids can readily cross cell membranes in their uncharged forms and then dissociate, thereby acidifying the cell interior (Karuri et 
Figure 3. Cytosolic $\mathrm{pH}$ changes induced by organic acids and $\mathrm{NH}_{4} \mathrm{Cl}$ in neuronal soma. One-day-old Xenopus cultures were loaded with BCECF-AM, and ratio fluorometric measurements of intracellular $\mathrm{pH}$ were made on single soma. A, Top panel: the area of single soma for the measurement of $\mathrm{pH}_{\mathrm{i}}$ was outlined by the dotted box. Scale bar, $20 \mu \mathrm{m}$. Bottom panel: tracellular pH. $B$, Replacement of all $\mathrm{NaCl}$ in Ringer's solution with sodium acetate resulted in a marked cytosolic acidification. $C$, Addition of $\mathrm{NH}_{4} \mathrm{Cl}$ to the bath caused cytosolic alkalinization. $D$, Summarized effect on cytosolic $\mathrm{pH}$ by the changes of external $\mathrm{pH}$ or by the addition of organic acids or $\mathrm{NH}_{4} \mathrm{Cl}$. Data are presented as mean $\pm \operatorname{SEM}(n=4-8)$. change of external $\mathrm{pH}$ slightly affected the in-
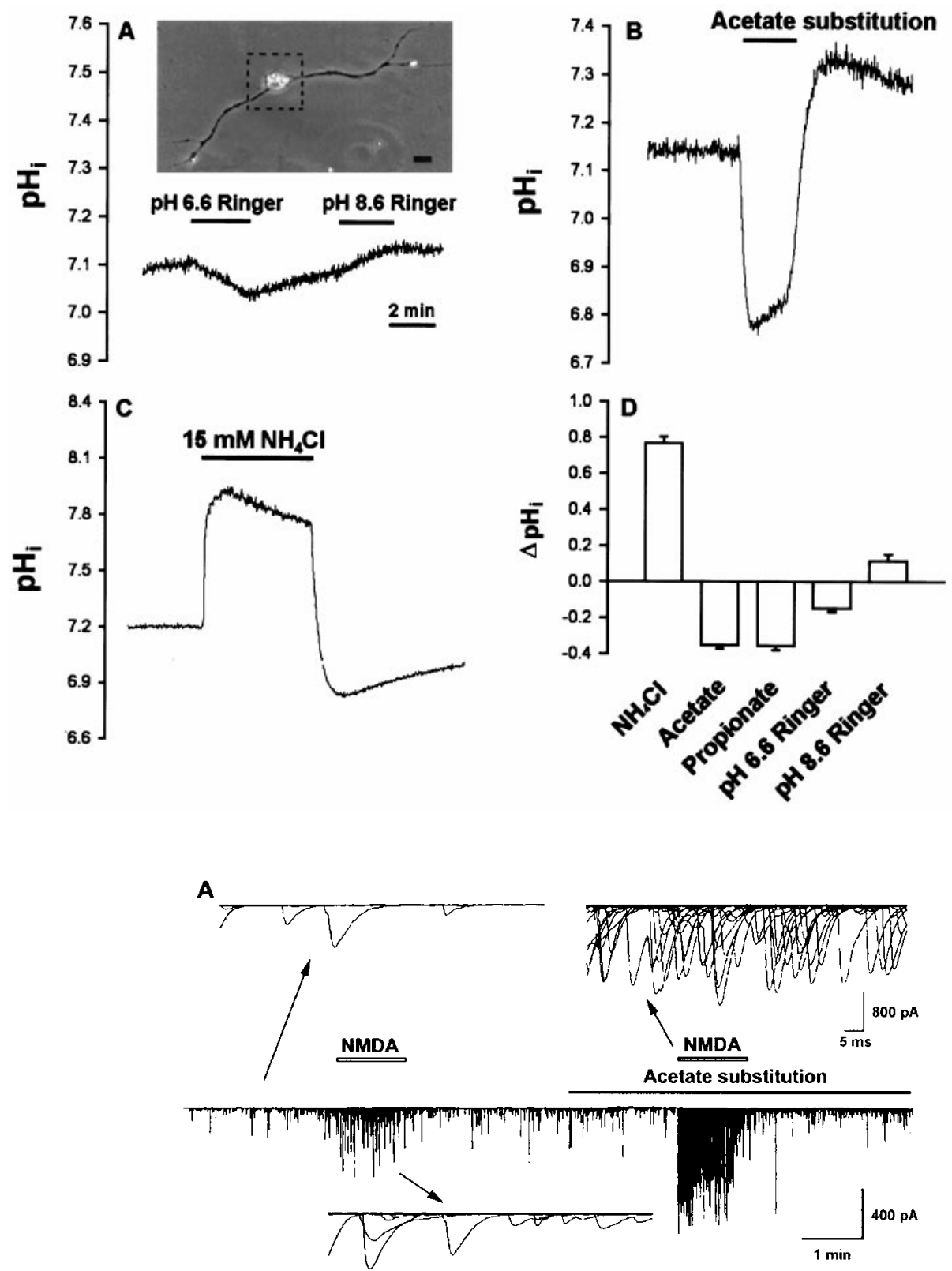

B

NMDA

NMDA

Propionate substitution

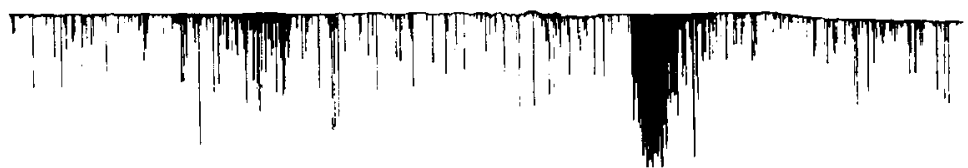

C

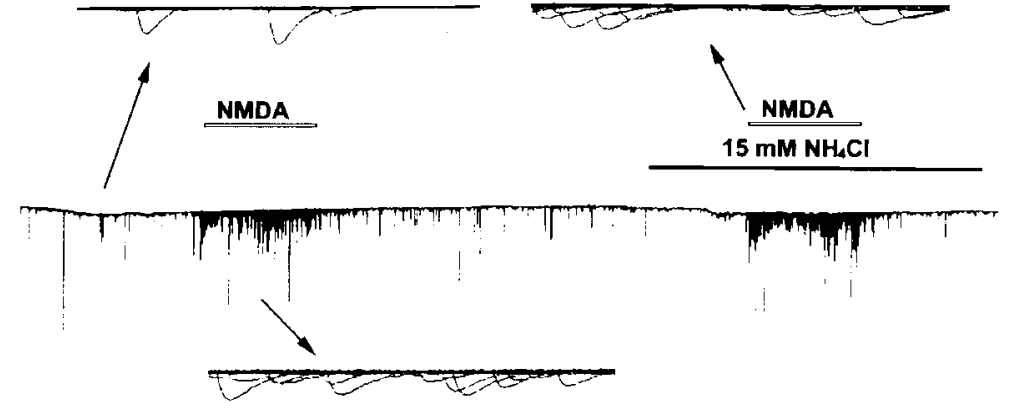

Figure 4. Effect of intracellular $\mathrm{pH}$ changes on the SSCincreasing action of NMDA. Shown is a continuous tracing of SSCs recorded from an innervated muscle cell in 1-d-old Xenopus laevis culture. The myocyte was voltage-clamped at a potential of $-60 \mathrm{mV}$. Downward deflections are SSCs (filtered at $150 \mathrm{~Hz}$ ). Perfusion of NMDA at synaptic region with another micropipette increased SSC frequency. NMDA responses were potentiated by cytosolic acidification with organic acid substitution and not significantly affected by cytosolic alkalinization with $\mathrm{NH}_{4} \mathrm{Cl}$. Samples of superimposed SSCs in $1 \mathrm{sec}$ before and after NMDA treatment are shown at higher time resolution. 

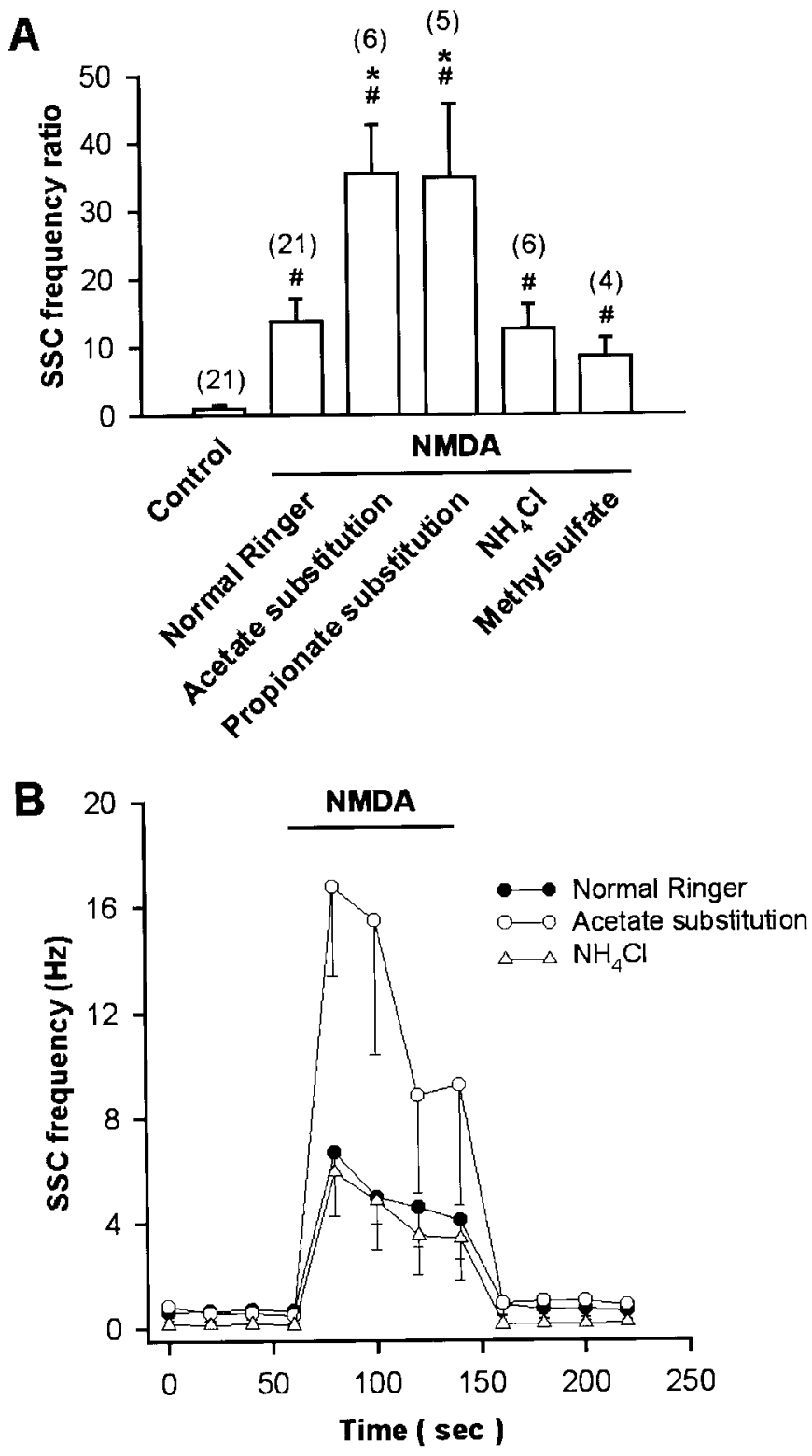

Figure 5. Summary of the effects of intracellular $\mathrm{pH}$ changes on the SSC-increasing action of NMDA. Note that NMDA increased SSC frequency in normal Ringer's solution, and intracellular acidification with either acetate or propionate potentiated NMDA responses $(A)$. $B$, Time course-response curves of the NMDA action on the cytosolic $\mathrm{pH}$ changes. Data are presented as mean $\pm \operatorname{SEM}(n)$. \# $p<0.05$ compared with control. ${ }^{*} p<0.05$ compared with NMDA in normal Ringer's solution.

al., 1993). Once inside the cell, the $\mathrm{pH}_{\mathrm{i}}$ is well above $\mathrm{p} K_{\mathrm{a}}$, leading to the dissociation of the protonated form and intracellular acidification. Therefore, the anions of weak acids such as acetate $\left(\mathrm{p} K_{\mathrm{a}}\right.$ $4.75)$ or propionate $\left(\mathrm{p} K_{\mathrm{a}} 4.87\right)$ caused larger internal acidification $\left(\mathrm{pH}_{\mathrm{i}} \fallingdotseq 6.8\right)$, and the anions of strong acids such as methylsulfate $\left(\mathrm{p} K_{\mathrm{a}}<1.0\right)$ induced little $\mathrm{pH}_{\mathrm{i}}$ change of the cells (Chesler, 1990).

The potentiation of NMDA action was in parallel with the levels of cytosolic acidification by these organic acids. We found no effect on NMDA response by methylsulfate substitution, ruling out the likelihood that the $\mathrm{Cl}^{-}$substitution itself was affecting NMDA receptor. Modulation of the NMDA-activated current by external $\mathrm{pH}$ changes resulted primarily from changes in the number of channel openings. The single-channel conductance of
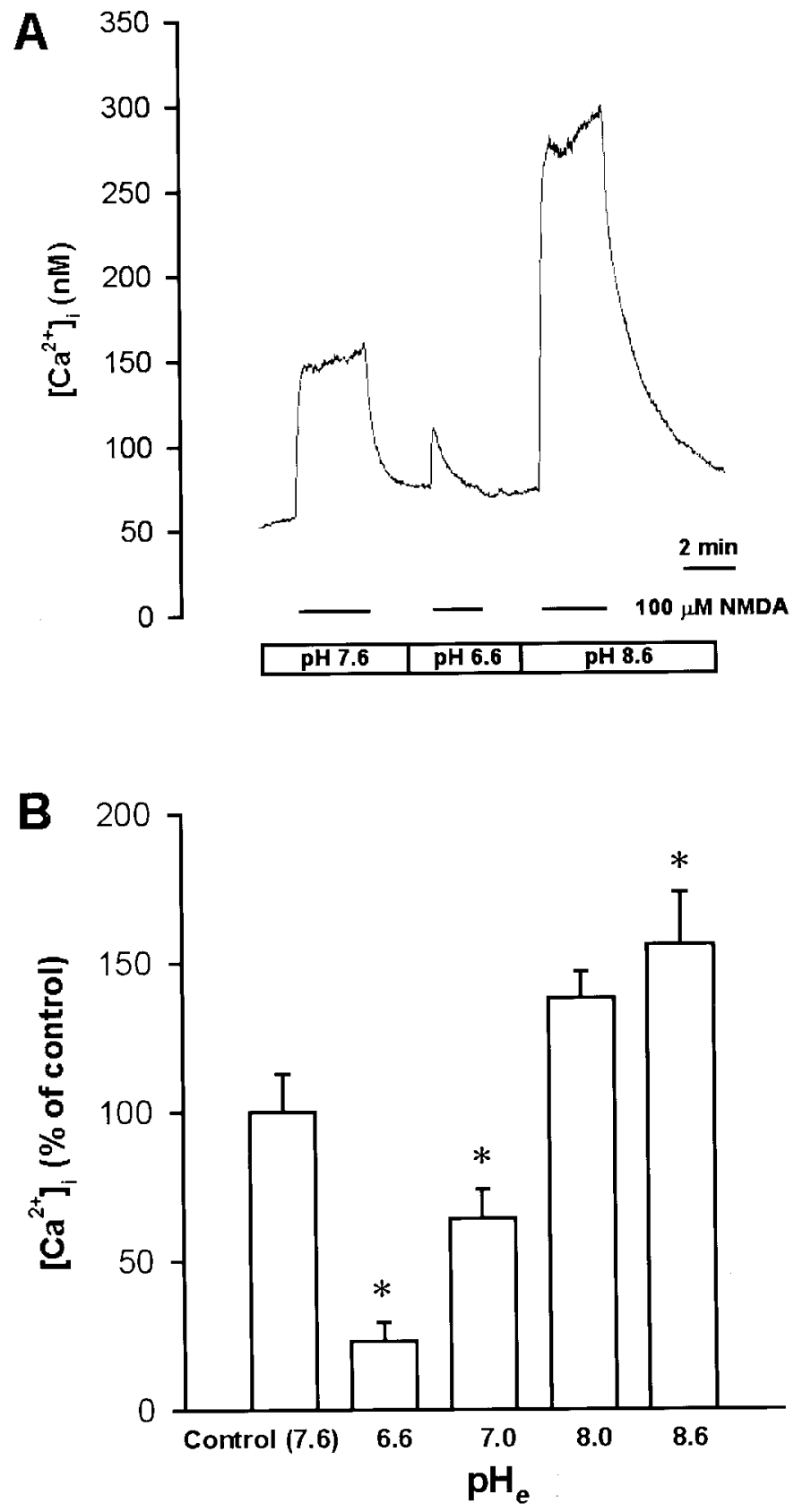

Figure 6. Effect of external $\mathrm{pH}$ changes on the $\left[\mathrm{Ca}^{2+}\right]$ i-increasing action of NMDA. A, Xenopus nerve-muscle cultures were loaded with fura-2 $\mathrm{AM}$, and ratio fluorometric measurement of intracellular $\mathrm{Ca}^{2+}$ was made on a single soma. Superfusion with NMDA increased $\left[\mathrm{Ca}^{2+}\right] i$, and this response was potentiated in $\mathrm{pH} 8.6$ Ringer's solution and antagonized in $\mathrm{pH}$ 6.6 Ringer's solution. $B$, Summary of the effect of external $\mathrm{pH}$ changes on the $\left[\mathrm{Ca}^{2+}\right] i$-increasing action of NMDA. Data are presented as mean $\pm \operatorname{SEM}(n=4) .{ }^{*} p<0.05$ compared with control.

NMDA receptor was not significantly affected (Tang et al., 1990; Vyklicky et al., 1990; Traynelis and Cull-Candy, 1991). We here confirmed previous reports that external alkalinization enhances and external acidosis inhibits NMDA receptor activation (Tang et al., 1990; Vyklicky et al., 1990; Traynelis and Cull-Candy, 1991; Takahashi and Copenhagen, 1996). A lowering of $\mathrm{pH}_{\mathrm{e}}$ from 7.6 to 6.6 inhibits the functional activation of NMDA receptors, whereas a rise of $\mathrm{pH}_{\mathrm{e}}$ from 7.6 to 8.6 significantly enhanced NMDA responses. However, we provide additional evidence that 

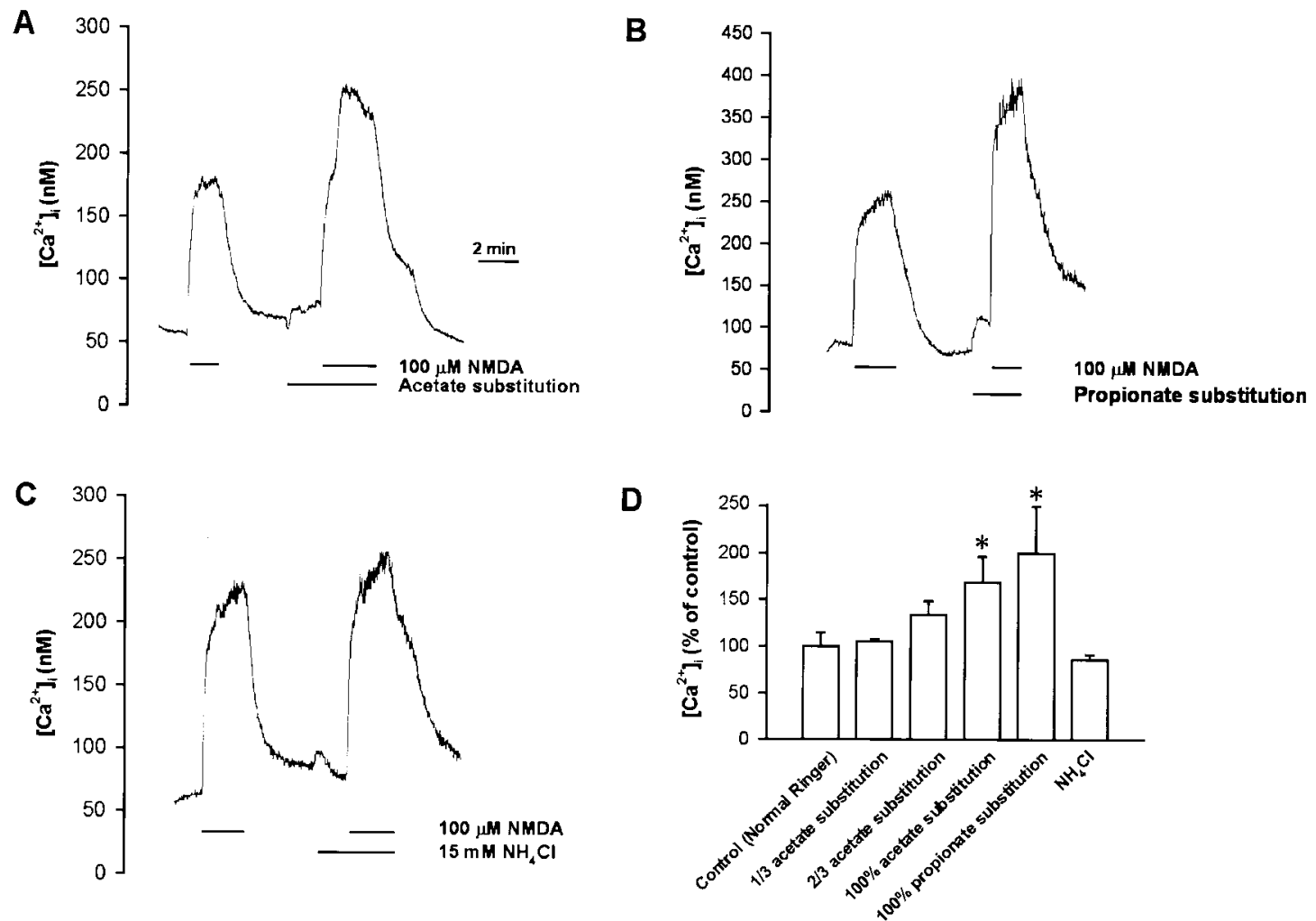

Figure 7. Effect of intracellular $\mathrm{pH}$ changes on the $\left[\mathrm{Ca}^{2+}\right] i$-increasing action of NMDA. Xenopus nerve-muscle cultures were loaded with fura 2-AM, and ratio fluorometric measurement of intracellular $\mathrm{Ca}^{2+}$ was made on a single soma. Superfusion with NMDA increased [Ca $\left.{ }^{2+}\right] i$, and this response was enhanced by cytosolic acidification with either acetate $(A)$ or propionate $(B)$ but not affected by cytosolic alkalinization with $\mathrm{NH}_{4} \mathrm{Cl}(C)$. $D$, Summary of the effects of intracellular $\mathrm{pH}$ changes on the $\left[\mathrm{Ca}^{2+}\right] i$-increasing action of NMDA. Data are presented as mean \pm SEM $(n=3-22) .{ }^{*} p<$ 0.05 compared with control.

Figure 8. Potentiation of NMDA-induced current by intracellular acidification. $A$, The soma of an isolated neuron was whole-cell voltage-clamped at $-60 \mathrm{mV}$. Local perfusion with NMDA from a glass micropipette $(N M D A)$ as indicated in the right panel induced an inward current. NMDA-induced current was enhanced by intracellular acidification with either acetate $(A)$ or propionate $(B)$ but not affected by cytosolic alkalinizaA

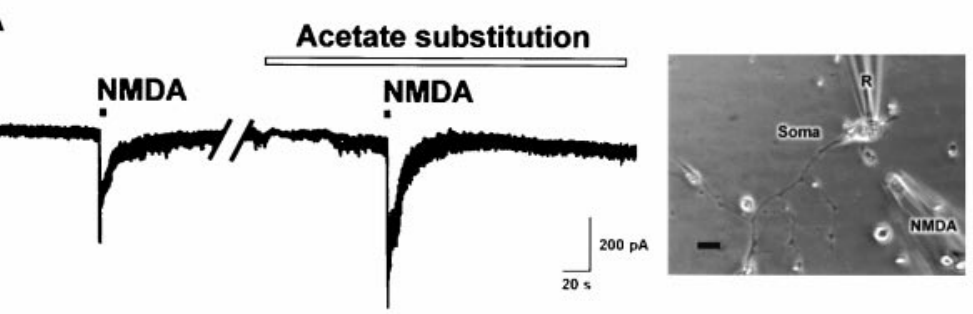

B

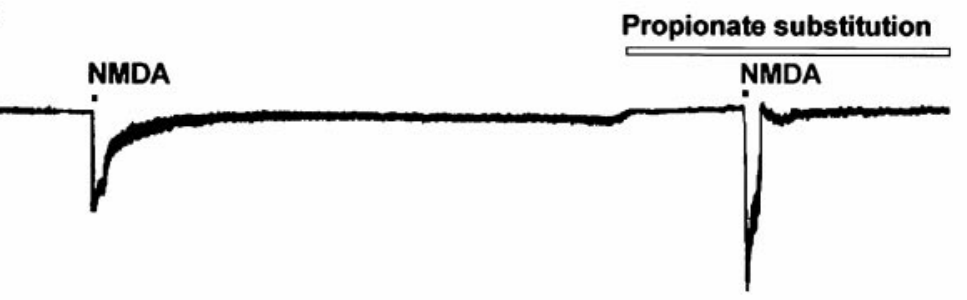

C

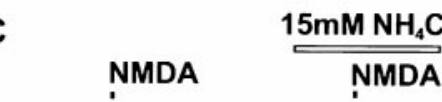

Propionate substitution tion $(C)$. Scale bar, $10 \mu \mathrm{m}$. $R$, Patch pipette. 
the function of the NMDA receptor can also be regulated by the changes of intracellular $\mathrm{pH}$. The potentiation of SSC and an increase in intracellular free $\mathrm{Ca}^{2+}$ by NMDA are regulated in parallel. We found previously that a larger decrease of $\mathrm{pH}_{\mathrm{i}}$ ( $\sim 1.4-1.6 \mathrm{pH}$ units) is required for SSC frequency-increasing effect by weak organic acid substitution in $\mathrm{pH}_{\mathrm{e}} 6.6$ Ringer's solution (Chen et al., 1998). In the current study, the intracellular fluid revealed an acidific shift in $\mathrm{pH}$ of only $0.2-0.4$ units by weak organic acid substitution in normal Ringer's solution. Therefore, the potentiation effect on SSC frequency can be fully accounted for by changes in the NMDA-induced $\left[\mathrm{Ca}^{2+}\right]_{\mathrm{i}}$ increase. Furthermore, direct evidence is shown in Figure 8 that NMDA-induced inward currents were increased in the presence of acetate or propionate. On the other hand, intracellular alkalinization had no significant effect on these NMDA responses. Because the NMDA receptor is activated in the absence of glycine, the modulation of intracellular $\mathrm{H}^{+}$appears not to be related to the glycine recognition site of the NMDA receptor. How the internal $\mathrm{H}^{+}$modulates the gating of the NMDA channel needs further investigation. Although $\mathrm{pH}_{\mathrm{i}}$ was reduced by 0.1 units after the $\mathrm{pH}_{\mathrm{e}}$ was lowered from 7.6 to 6.6, no potentiation of NMDA responses was observed, probably because of the larger inhibitory effect on NMDA receptors by external acidification and the insufficient intracellular acidification.

Changes in the concentration of $\mathrm{H}^{+}$have been clearly shown to serve important biological roles by regulating the properties of protein macromolecules. Accumulating evidence suggests that extracellular and intracellular $\mathrm{pH}$ can change significantly under not only pathological but also physiological circumstances. The local $\mathrm{pH}$ shifts could be large in synaptic cleft and subsynaptic regions under these conditions. Repetitive neuronal activity may lower intracellular $\mathrm{pH}$ through several mechanisms. These include the metabolic production of $\mathrm{CO}_{2}$ and lactic acid, the release of protons from internal sites in response to elevation of free intracellular $\mathrm{Ca}^{2+}$ concentration, and the net entry of acid through ligand- or voltage-gated channels (Chesler and Kaila, 1992). Brief exposure of hippocampal neurons to NMDA results in a concentration-dependent $\mathrm{pH}_{\mathrm{i}}$ reduction (0.2-0.4 $\mathrm{pH}$ units) (Irwin et al., 1994). Acute focal electrical stimulation evoked an intracellular acidosis of approximately $\mathrm{pH} 6.8$ in cortical tissue (Yaksh and Anderson, 1987). Changes in $\mathrm{pH}_{\mathrm{i}}$ and $\mathrm{pH}_{\mathrm{e}}$ have been known to modify several types of voltage-gated ion channels (Takahashi and Copenhagen, 1996). Modulation of excitatory transmission by $\mathrm{pH}$ shifts may be especially pertinent to forms of long-term potentiation (LTP) that have been linked to NMDA receptor activation (Blanton et al., 1989). Experimentally, LTP is often induced by trains of high frequency stimulation. Both the intracellular and external $\mathrm{pH}$ shifts may thus influence the relationship between LTP induction and stimulus frequency. Pathologically, hypoxia and glucose depletion in hippocampal slices have also been shown to result in a decrease in $\mathrm{pH}_{\mathrm{i}}$ within 5 min of exposure (Chesler, 1990). Furthermore, brain ischemia has been reported to lower brain $\mathrm{pH}_{\mathrm{e}}$ and $\mathrm{pH}_{\mathrm{i}}$ (Nedergaard et al., 1991; Fujiwara et al., 1992). Recent evidence suggests that mild extracellular acidosis protects central neurons from injury induced by oxygen and glucose deprivation (Giffard et al., 1990; Tombaugh and Sapolsky, 1990). Extracellular acidosis prevents the activation of NMDA receptors, which play a major role in mediating ischemic neuronal injury. By contrast, extracellular alkalosis can induce epileptiform activity, which is blocked by NMDA antagonists in mammalian brain slices (Aram and Lodge, 1987). Our results showed that intracellular acidic shift in $\mathrm{pH}$ of only 0.2-0.4 units enhanced NMDA responses. Therefore, intracellular acidosis may enhance NMDA responses in some physiological conditions and NMDA neurotoxicity in certain pathological diseases. The proton sensitivity of NMDA receptors could influence synaptic plasticity and seizure generation and may be relevant for glutamate-induced neurotoxicity during ischemia. These results add another level of complexity to the regulation of NMDA synaptic events by endogenous factors. Intracellular $\mathrm{H}^{+}$, acting as a second messenger, may influence the neuronal excitability via modulation of NMDA channel activity.

\section{REFERENCES}

Aram JA, Lodge D (1987) Epileptiform activity induced by alkalosis in rat neocortical slices: block by antagonists of $N$-methyl-D-aspartate. Neurosci Lett 83:345-350.

Beal MF (1992) Does impairment of energy metabolism result in excitotoxic neuronal death in neurodegenerative illnesses? Ann Neurol 31:119-130.

Blanton MG, Lo Turco JJ, Kriegstein AR (1989) Whole cell recording from neurons in slices of reptilian and mammalian cerebral cortex. J Neurosci Methods 30:203-210.

Chen YH, Wu ML, Fu WM (1998) Regulation of acetylcholine release by intracellular acidification at developing motoneurons in Xenopus cell cultures. J Physiol (Lond) 507.1:41-53.

Chesler M (1990) The regulation and modulation of $\mathrm{pH}$ in the nervous system. Prog Neurobiol 34:401-427.

Chesler M, Kaila K (1992) Modulation of $\mathrm{pH}$ by neuronal activity. Trends Neurosci 15:396-402.

Choi DW (1990) Cerebral hypoxia: some new approaches and unanswered questions. J Neurosci 10:2493-2501.

Choi DW (1992) Excitotoxic cell death. J Neurobiol 23:1261-1276.

Dingledine R, McBain CJ, McNamara JO (1990) Excitatory amino acid receptors in epilepsy. Trends Pharmacol Sci 11:334-338.

Dixon DB, Takahashi K, Copenhagen DR (1993) L-glutamate suppresses HVA calcium current in catfish horizontal cells by raising intracellular proton concentration. Neuron 11:267-277.

Edres WK, Ballanyi K, Serve B, Grafe P (1986) Excitatory amino acids and intracellular $\mathrm{pH}$ in motoneurons of the isolated spinal cord. Neurosci Lett 72:54-58.

Foster AC, Fagg GE (1984) Acidic amino acid binding sites in mammalian neuronal membranes: their characteristics and relationship to synaptic receptors. Brain Res Rev 7:103-164.

Fu WM, Liou JC, Lee YH, Liou HC (1995) Potentiation of neurotransmitter release by activation of presynaptic glutamate receptors at developing neuromuscular synapses of Xenopus. J Physiol (Lond) 489.3:813-823.

Fujiwara N, Abe T, Endoh H, Warashina A, Shimoji K (1992) Changes in intracellular $\mathrm{pH}$ of mouse hippocampal slices responding to hypoxia and/or glucose depletion. Brain Res 572:335-339.

Giffard RG, Monyer H, Christine CW, Choi DW (1990) Acidosis reduces NMDA receptor activation, glutamate neurotoxicity, and oxygen-glucose deprivation neuronal injury in cortical cultures. Brain Res 506:339-342.

Grynkiewicz G, Poenie M, Tsien RY (1985) A new generation of calcium indicators with greatly improved fluorescence properties. J Biol Chem 260:3440-3450.

Hamill OP, Marty A, Neher E, Sakmann B, Sigworth FJ (1981) Improved patch-clamp techniques for high-resolution current recording from cells and cell free membrane patches. Pflügers Arch 391:85-100.

Hartley Z, Dubinsky JM (1993) Changes in intracellular pH associated with glutamate oritotoxicity. J Neurosci 13:4690-4699.

Hollmann M, Heinemann S (1994) Cloned glutamate receptors. Annu Rev Neurosci 17:31-108.

Irwin RP, Lin SZ, Long RT, Paul SM (1994) $N$-methyl-D-aspartate induces a rapid, reversible, and calcium-dependent intracellular acidosis in cultured fetal rat hippocampal neurons. J Neurosci 14:1352-1362.

Israel M, Lesbats B, Bruner J (1993) Glutamate and acetylcholine release from cholinergic nerve terminals, a calcium control of the specificity of the release mechanism. Neurochem Int 22:53-58. 
Karuri AR, Dobrowsky E, Tannock IF (1993) Selective cellular acidification and toxicity of weak organic acids in an acidic microenvironment. Br J Cancer 68:1080-1087.

Liou HC, Yang RS, Fu WM (1996) Potentiation of spontaneous acetylcholine release from motor nerve terminals by glutamate in Xenopus tadpoles. Neuroscience 75:325-331.

McBain CJ, Mayer ML (1994) $N$-methyl-D-aspartic acid receptor structure and function. Physiol Rev 74:723-760.

Meister B, Arvidsson U, Zhang X, Jacobsson G, Villar MJ, Hokfelt T (1993) Glutamate transporter mRNA and glutamate-like immunoreactivity in spinal motoneurones. NeuroReport 5:337-340.

Meldrum BS (1992) Excitatory amino acids in epilepsy and potential novel therapies. Epilepsy Res 12:189-196.

Monaghan DT, Bridges RJ, Cotman CW (1989) The excitatory amino acid receptors: their classes, pharmacology, and distinct properties in the function of the central nervous system. Annu Rev Pharmacol Toxicol 29:365-402.

Nedergaard M, Kraig RP, Tanabe J, Pulsinelli WA (1991) Dynamics of interstitial and intracellular $\mathrm{pH}$ in evolving brain infarct. Am J Physiol 260:R581-R588.

Roos A, Boron WF (1981) Intracellular pH. Physiol Rev 61:296-434.

Tabti N, Poo MM (1991) Culturing spinal neurons and muscle cells from Xenopus embryos. In: Cultures of nerve cells (Banker G, Goslin K, eds), pp 139-153. Cambridge, MA: MIT.

Takahashi KI, Copenhagen DR (1996) Modulation of neuronal function by intracellular $\mathrm{pH}$. Neurosci Res 24:109-116.
Tang CM, Dichter M, Morad M (1990) Modulation of the $N$-methyl-Daspartate channel by extracellular $\mathrm{H}^{+}$. Proc Natl Acad Sci USA 87:6445-6449.

Tombaugh GC, Sapolsky RM (1990) Mild acidosis protects hippocampal neurons from injury induced by oxygen and glucose deprivation. Brain Res 506:343-345.

Traynelis SF, Cull-Candy SG (1991) Pharmacological properties and $\mathrm{H}^{+}$sensitivity of excitatory amino acid receptor channels in rat cerebellar granule neurones. J Physiol (Lond) 433:727-763.

Vyas S, Bradford HF (1987) Co-release of acetylcholine, glutamate and taurine from synaptosomes of Torpedo electric organ. Neurosci Lett $82: 58-64$.

Vyklicky L, Vlachova V, Krusek J (1990) The effect of external pH changes on responses to excitatory amino acids in mouse hippocampal neurones. J Physiol (Lond) 430:497-517.

Watkins JC, Evans RH (1981) Excitatory amino acid transmitters. Annu Rev Pharmacol Toxicol 21:165-204.

Wu ML, Tsai ML, Tseng YZ (1994) DIDS-sensitive pHi-regulation in single cardiac myocytes in nominally $\mathrm{HCO}_{3}{ }^{-}$-free conditions. Circ Res 75:123-132

Xie ZP, Poo MM (1986) Initial events in the formation of neuromuscular synapse: rapid induction of acetylcholine release from embryonic neuron. Proc Natl Acad Sci USA 83:7069-7073.

Yaksh TL, Anderson RE (1987) In vivo studies on intracellular $\mathrm{pH}$, focal flow, and vessel diameter in the cat cerebral cortex: effects of altered $\mathrm{CO}_{2}$ and electrical stimulation. J Cereb Blood Flow Metab 7:332-341. 